\title{
STATIC ANALYSIS OF SINGLE-AXLE TRACTOR TRIALER FRAME
}

\author{
Jan Dizo $^{1}$, Miroslav Blatnicky ${ }^{1}$, Stanislav Semenov ${ }^{2}$, Evgeny Mikhailov ${ }^{2}$, Rafal Melnik ${ }^{3}$, Jakub Kurtulik ${ }^{1}$ \\ ${ }^{1}$ University of Zilina, Slovakia; ${ }^{2}$ Volodymyr Dahl East Ukrainian National University, Ukraine; \\ ${ }^{3}$ Lomza State University of Applied Sciences, Poland \\ jan.dizo@fstroj.uniza.sk,miroslav.blatnicky@fstroj.uniza.sk, semenov@snu.edu.ua, \\ mihajlov@snu.edu.ua,rmelnik@pwsip.edu.pl
}

\begin{abstract}
A tractor trailer is a nonautomotive vehicle, which is in its construction itself intended for transport of materials, mainly of agricultural commodities. We can recognize several types of tractor trailers. There are flat trailers, which platform allows transporting many kinds of materials, however, it does not allow to unload without an additional machine or manpower. A tipping trailer body significantly makes easier manipulation mainly with bulk material, such as gravel, send, soil, etc., and, at the same time, if the tipping body is properly designed, it allows also to transport palletised materials and more other commodities, which occur in agriculture. A possibility of tipping trailer body makes such a trailer very universal. However, the design of such a trailer requires to take into account certain specific facts, which do not occur in a case of a common platform-type trailer body. On the one hand, these specific requirements consist in operational conditions, in which a set of a tractor and a trailer can get to, and on the other hand, they result from different loading of a trailer frame in case of tipping. The authors in the article present the static analysis of such trailer structure, namely its main body. The presented problem is a part of the process of the design of a new type of a trailer, which a commercial producer wants to approve for production and operation. As it is a three-way tipping trailer, from the static analysis point of view, designers of the trailer have to take into account the limited loading case, which the trailer can be in. The part of the presented work are numerical calculations and strength analysis of the trailer frame structure under defined loading cases. Strength analyses were carried out by means of the finite element method. The article includes presentation of a computational model of a frame, the definition of the boundary conditions and the results of analyses.
\end{abstract}

Keywords: single-axle trailer, static analysis, frame, finite element method.

\section{Introduction}

A term tractor trailer means tractor trailers and semi-trailers, which are intended to transport materials, mainly agricultural commodities. Based on the technical construction, trailers and semitrailers can be divided in several types, such as flatbed trailers, tipper trailers or special trailers equipped by a specific superstructure (bulk, tank etc.) $[1 ; 2]$. The article presents a design of a frame of a singleaxle tractor trailer, which will use a tipper superstructure. Such a system will allow to unload the transported goods by an easy way to three sides. A tipping process is realized by a hydraulic cylinder, which is located in the centre part of the frame. Changing of the tipping side is ensured by restraining the particular ball joint. Also, an axle of the trailer will be mounted to the frame. As it is an agricultural transport means, it will be usually used in rough terrain conditions. It means, the frame will be exposed to considerable loads. Taking into account these facts, the designed trailer frame should meet the requirements of structure integrity, reliability and lifetime [3-5].

\section{Materials and methods}

Defining of inputs is the basic step in designing of the structure. Another important elements related with the design of the trailer frame come from it. Determining of input parameters is very important in terms of boundary conditions and individual loads for the strength analysis.

The main goal of activities has been to design a middle-class tractor trailer with a single axle. All dimensions, such as the total length, width and height, all weight (including curb weight, total weight), the maximal speed and others, meet all requirements introduced in the promulgation [6], as well as European regulations [7; 8]. The total length is of $4.497 \mathrm{~m}$, the total width is of $1.960 \mathrm{~m}$ and the total height including sidewalls is of $1.820 \mathrm{~m}$. These dimensions are indicated in Fig. 1. The payload of the trailer is designed of $3000 \mathrm{~kg}$ and the total weight of the trailer will be of $4500 \mathrm{~kg}$. Hence, the curb weight is of $1500 \mathrm{~kg}$. The trailer is proposed to be operated at the maximal speed of $40 \mathrm{~km} \cdot \mathrm{h}^{-1}$. The trailer belongs to the R3a category [9]. Dynamical effects of the load are taken into account by the dynamic coefficient $\delta_{D}=1.5$. This value represents driving of the trailer on fortified roads and on terrain without considerable irregularities $[10 ; 11]$. In case of driving in rougher terrain, the driving speed must be reduced according to the trailer manual. 

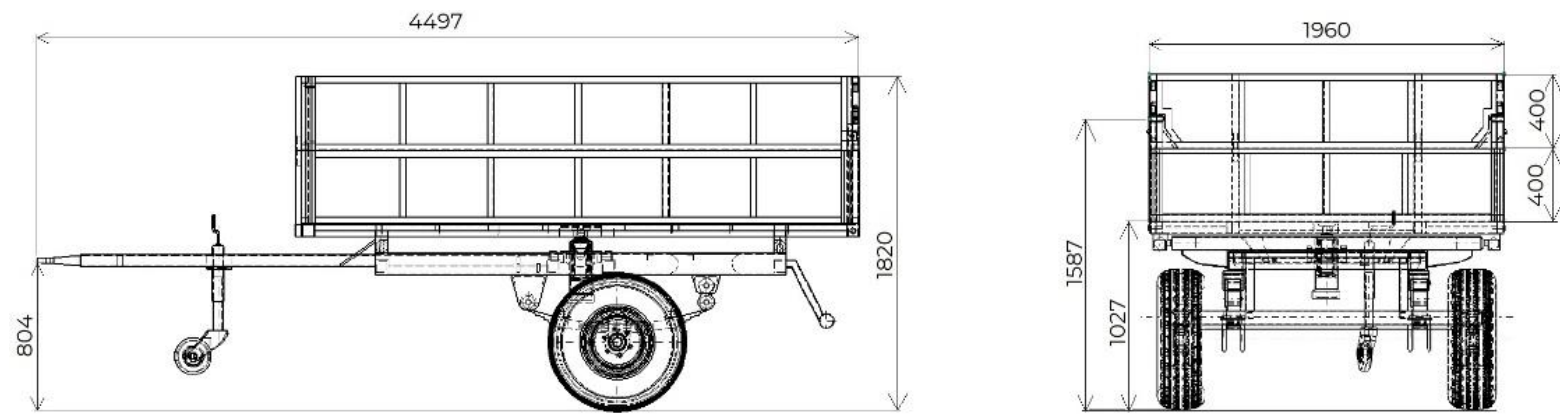

Fig. 1. Trailer main dimensions

The trailer structure consists of two basic frames, i.e. the chassis frame and the superstructure frame.

The calculations of strength are focused on the chassis frame. The chassis frame is formed by closed and open profiles. They are made of S355J0 steel. Its yield of the strength $R_{e}$ is of $355 \mathrm{MPa}$ and the ultimate strength $R_{m}$ is of 470 to $630 \mathrm{MPa}$ [12]. Individual profiles are connected by welding joints.

The chassis frame includes the main carrying elements with dimensions of 70x70x5 mm. The bottom part of these profiles is adjusted for mounting of suspension elements. In the centre part of the frame, lateral and longitudinal stiffeners are welded. They also serve for mounting the hydraulic cylinder. In front and rear parts of the basic structure, ball joints are located for mounting the tipping superstructure. These ball joints allow three-way tipping. A drawbar is in the front part of the trailer and an underrun protection in the form of a steel tube is in the rear part of the trailer. The frame structure also includes other steel elements, which strengthen the frame structure. A CAD model of the designed trailer frame is depicted in Fig. 2. Static analyses have been carried out in a commercial FEM software $[13 ; 14]$. For these purposes, it has been necessary to determine the boundary conditions. They include definitions of acting loads and definitions of degrees of freedom.

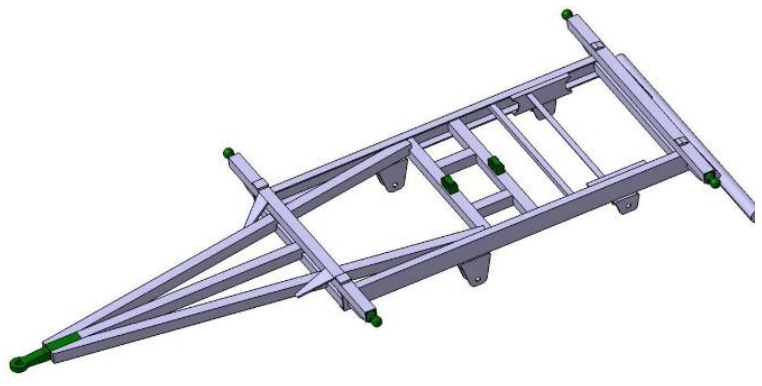

Fig. 2. CAD model of the analysed frame

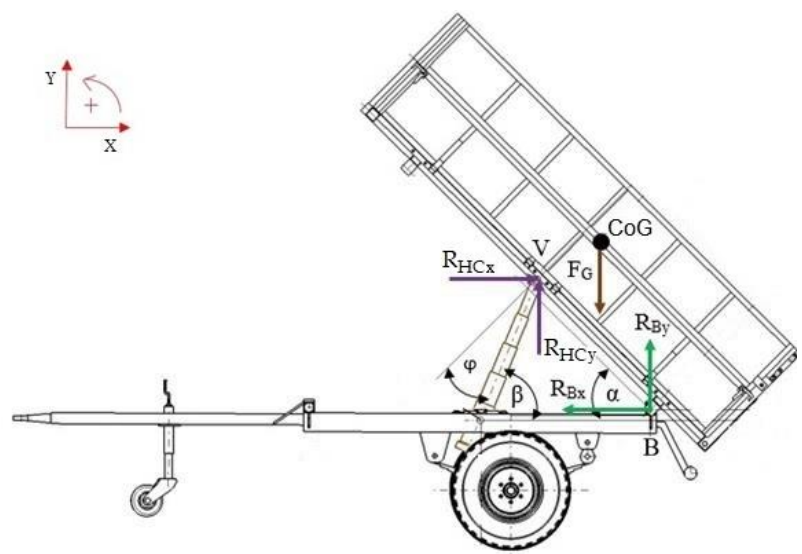

Fig. 4. Reactions during back tipping

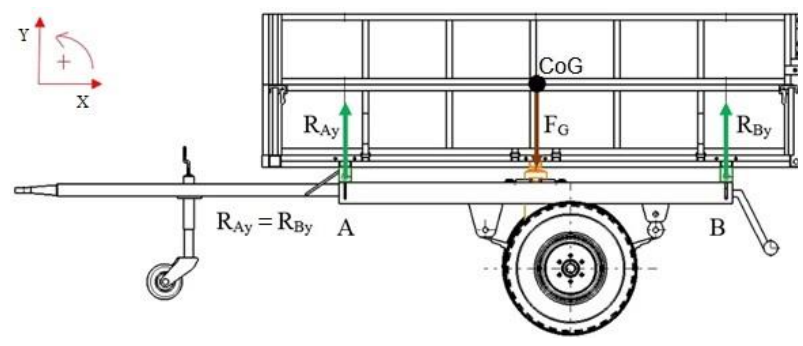

Fig. 3. Reactions for the straight surface

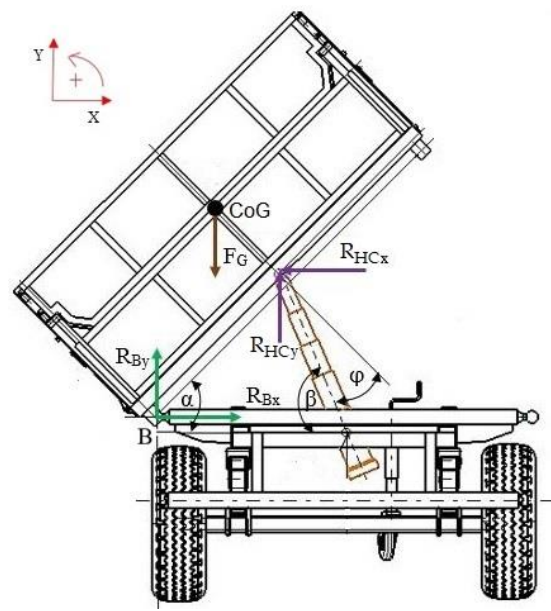

Fig. 5. Reactions during side tipping

Acting loads have been calculated for three basic load cases as following: 
- The trailer is on a straight surface (Fig. 3).

- The maximal back tipping angle of $50^{\circ}$ (Fig. 4).

- The maximal side tipping angle of $45^{\circ}$ (Fig. 5).

The first load case represents a situation, when the trailer is being in the static position on a straight surface or when it is moving on a straight surface at a constant speed (Fig. 3). Hence, the chassis frame is loaded by the goods weight and by the superstructure mass, both loads due to the gravitational acceleration of $9.81 \mathrm{~m} \cdot \mathrm{s}^{-1}$. The superstructure rests on all four ball joints. The dynamic coefficient mentioned above $\delta_{D}$ is taken into account.

The second load case is for the back tipping of the superstructure. The trailer is being at rest and the superstructure is tilted to the maximal position of $50^{\circ}$ (Fig. 4). During the tipping process the load of $3000 \mathrm{~kg}$ is considered. It is due to the reason that in extreme winter conditions the load can freeze to the superstructure, or, that the superstructure rear end will not work properly, and it will be closed. The superstructure rests on two rear ball joints and on a pivot joint of the hydraulic cylinder placed in the centre of the frame.

The third load case considers a situation, when the superstructure is tilted on the side (Fig. 5). For this it does not matter on which one. The trailer is again in the static position. The maximal tipping angle is $45^{\circ}$. All calculations consider the load of $3000 \mathrm{~kg}$. Again in this case, the most unfavourable case is the extreme condition, i.e. the load is frozen to the superstructure bottom or that the sidewall is closed. The superstructure rests on the two ball joints and the centre of the pivot joint. However, two ball joints on one side in the longitudinal direction are considered.

Reactions are calculated analytically by means of a free body diagram method and related equations of equilibrium. The general form is as following:

$$
\begin{aligned}
& \sum_{i} F_{x i}=0 \\
& \sum_{i} F_{y i}=0, \\
& \sum_{i} M_{i}=0
\end{aligned}
$$

where $\quad F_{x i}$ - forces acting in $x$-direction, $\mathrm{N}$;

$F_{y i}-$ forces acting in $y$-direction, $\mathrm{N}$;

$M_{i}-$ moments acting about the chosen axis, $\mathrm{Nm}$.

The application of the mentioned method is well-known. Describing of analytical calculations of reactions for all load cases would significantly extend the range of the article. Therefore, their details are not included and important results are listed in Table 1. Individual rows include numerical values of calculated quantities for the described load cases, which are marked as following:

- $\quad R_{A x}$ - reaction in the $x$ direction of the ball joint.

- $R_{A y}$ - reaction in the $y$ direction of the ball joint.

- $R_{H C x}$ - reaction in the $x$ direction of the hydraulic cylinder.

- $R_{H C y}-$ reaction in the $y$ direction of the hydraulic cylinder.

It should be noted, that every load case has own coordinate system, i.e. $x$ and $y$ axes are considered individually for every free body diagram (Fig. 3, Fig. 4 and Fig. 5). The last column includes indication of individual figures containing a calculation scheme.

\begin{tabular}{|c|c|c|c|c|c|c|c|}
\hline \multirow{3}{*}{$\begin{array}{c}\text { Load } \\
\text { case }\end{array}$} & \multicolumn{6}{|c|}{ Values of calculated reactions, $\mathrm{kN}$} & \multirow{3}{*}{$\begin{array}{c}\text { Calculating } \\
\text { scheme }\end{array}$} \\
\hline & $\boldsymbol{R}_{B x}$ & $\boldsymbol{R}_{B y}$ & $\boldsymbol{R}_{B x}$ & $\boldsymbol{R}_{B y}$ & $\boldsymbol{R}$ & $\boldsymbol{R}_{\mathrm{H}}$ & \\
\hline & \multicolumn{2}{|c|}{ per two ball joints } & \multicolumn{2}{|c|}{ per one ball joint } & $\Lambda_{H C x}$ & 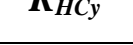 & \\
\hline First load case & - & 25.640 & - & 12.820 & - & - & Figure 3 \\
\hline Second load case & 0.296 & 0.272 & 0.148 & 0.136 & 0.296 & 33.916 & Figure 4 \\
\hline Third load case & 4.477 & 23.379 & 2.239 & 11.690 & 4.477 & 10.809 & Figure 5 \\
\hline
\end{tabular}

Table 1

Calculated reactions for individual load cases 
Within research of the described load cases, it is necessary to analyse individual structural units of the designed trailer. The chassis frame is the most important carrying part.

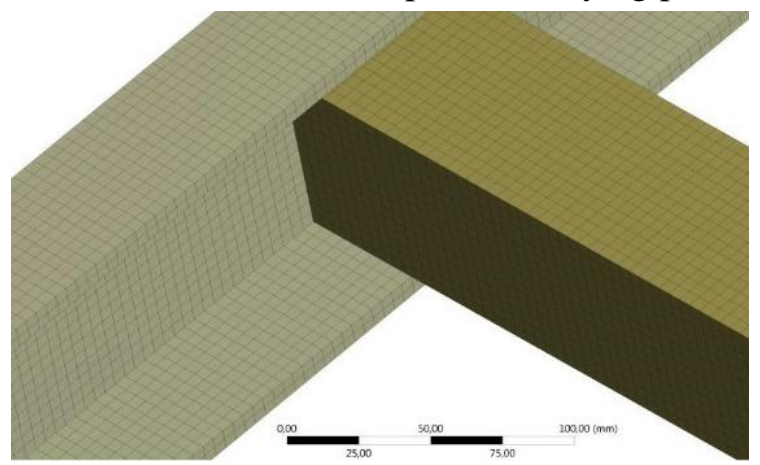

Fig. 6. Illustration of FEM mesh

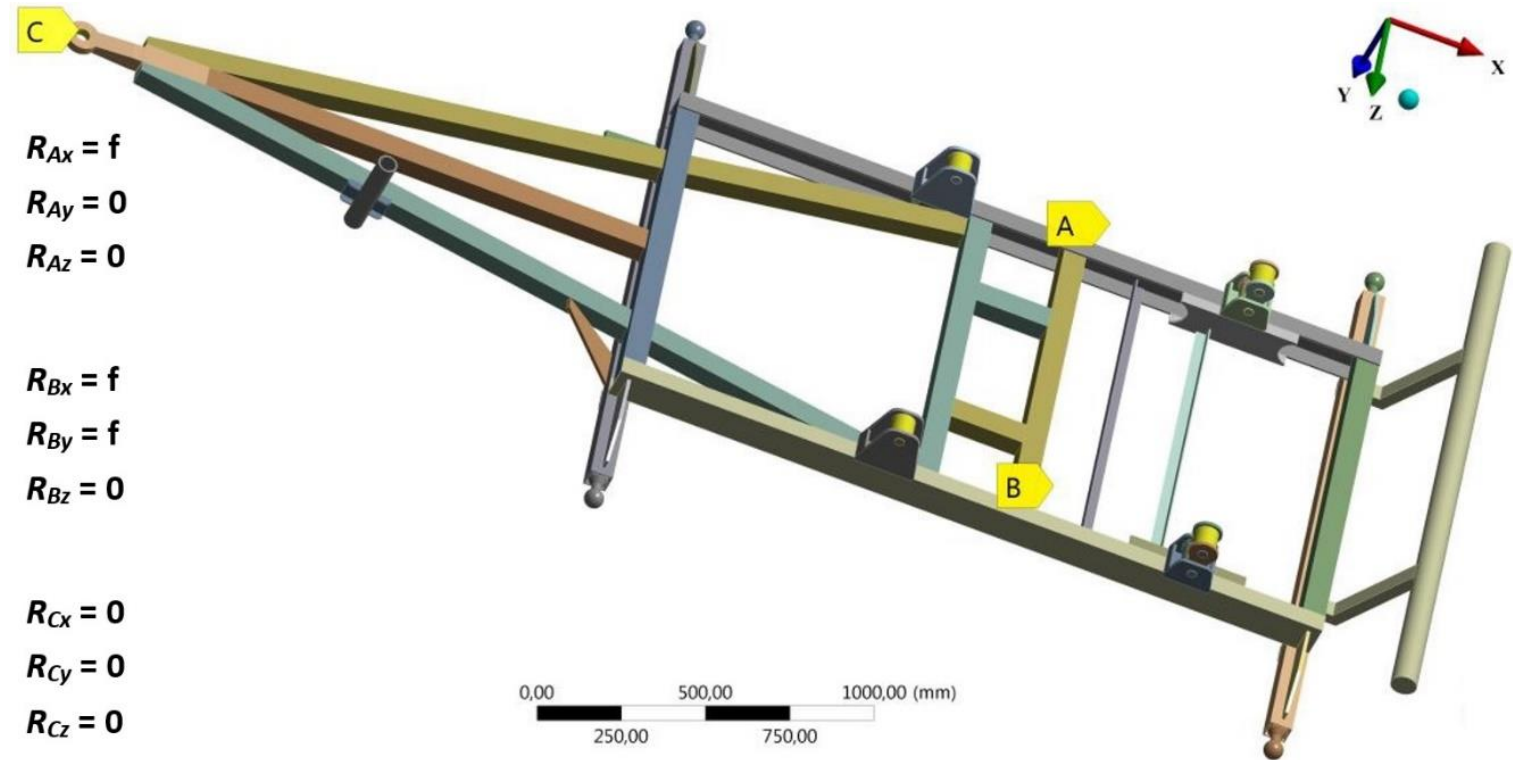

Fig. 7. Illustration of boundary condition (DOF) definition

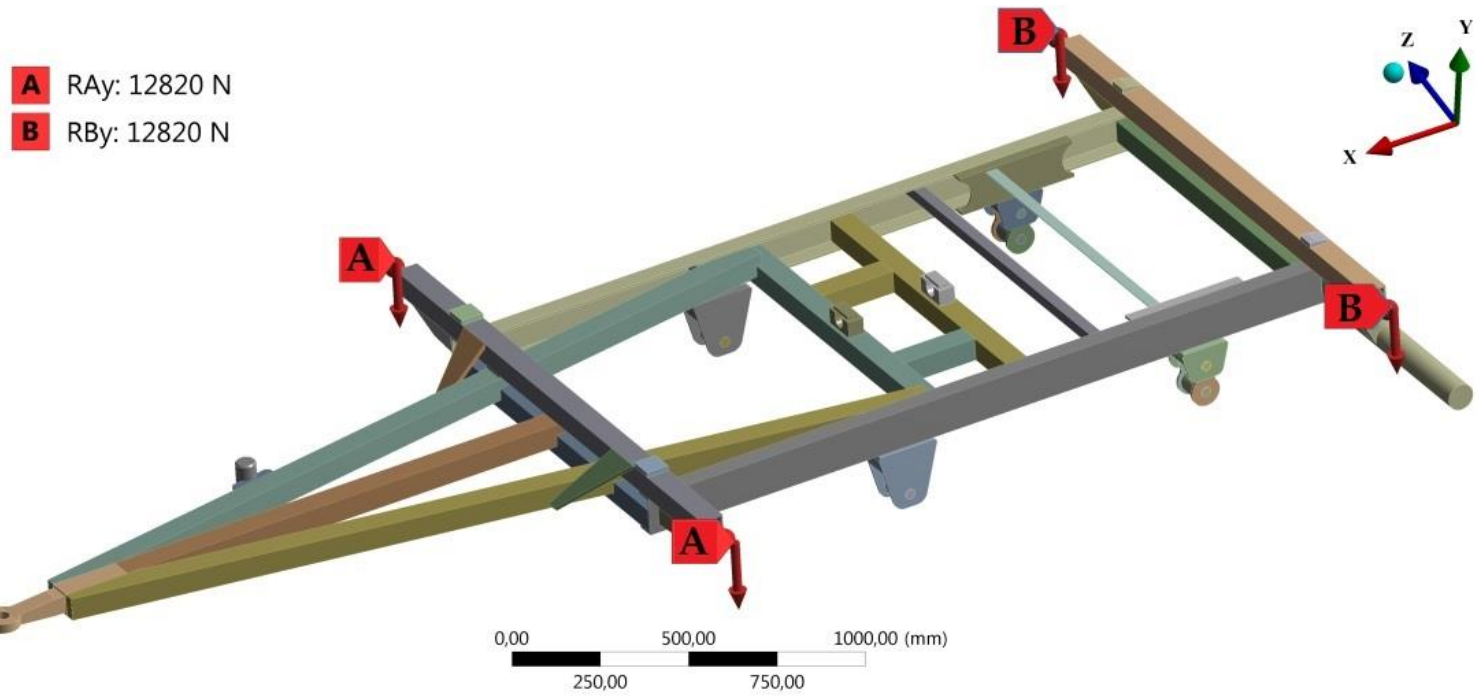

Fig. 8. Illustration of load definition for the first load case

This work presents static analysis. Its procedure includes several important follow-up steps. Firstly, it is necessary to create the geometry of the model. Subsequently, this geometry is imported to a simulation software. In our research, we have used the Ansys software package, which works based on the finite element method (FEM) $[15 ; 16]$. This simulation tool is suitable to perform considered 
analyses of the frame, because it allows well cooperation with the used CAD software Catia. A generated FE mesh is shown in Fig. 6. The next step, the definition of boundary conditions followed. This step has taken into account specifics of individual load cases. An example of the boundary conditions definition is depicted in Fig.7. As it can be seen, degrees of freedom were restrained for translation movements. The letter "f" means "free" motions and the number " 0 " means zero degrees of freedom. Rotational movements were defined as "free".

Figure 8 shows an example of definition of loads for the first load case. It comes from calculated values listed in Table 1. In the first load case, all ball joints are loaded by the forces with the same value, namely by the force of $12.820 \mathrm{~N}$.

It should be noted, that in principle, the FEM mesh and related FE elements (type, size) can be in our analysed structure defined in two ways. Either by volume elements or by shell elements using median planes. In the development phase of the trailer, both methods are used including various element sizes. This work presents just one way to analyse it with the reached results.

\section{Results and discussion}

For the first load case, degrees of freedom have been removed in the suspension system area and at the end of the drawbar. Values of load forces correspond to Table 1 and its placing to Fig. 3. Graphical output of the strength analysis is shown in Fig. 9.

Based on distribution of stress, calculated based on von Misses hypothesis, the maximal stresses in the structure meet the criterion to be lower than the yield of strength, i.e. lower than $355 \mathrm{MPa}$. We can observe that in weld location the stresses are acceptable except of one tight location, where the calculated stress achieved the value of $722.42 \mathrm{MPa}$. This high value is unique and it is supposed as a numerical error. Results achieved for other computational settings (type and size of finite elements) have shown a similar stress distribution. The maximal values of stress calculated in the ball joint structure achieves the value of $345.34 \mathrm{MPa}$. As this part is normalized and bought from a supplier, we suppose, this result is not critical and can be accepted for our purposes.

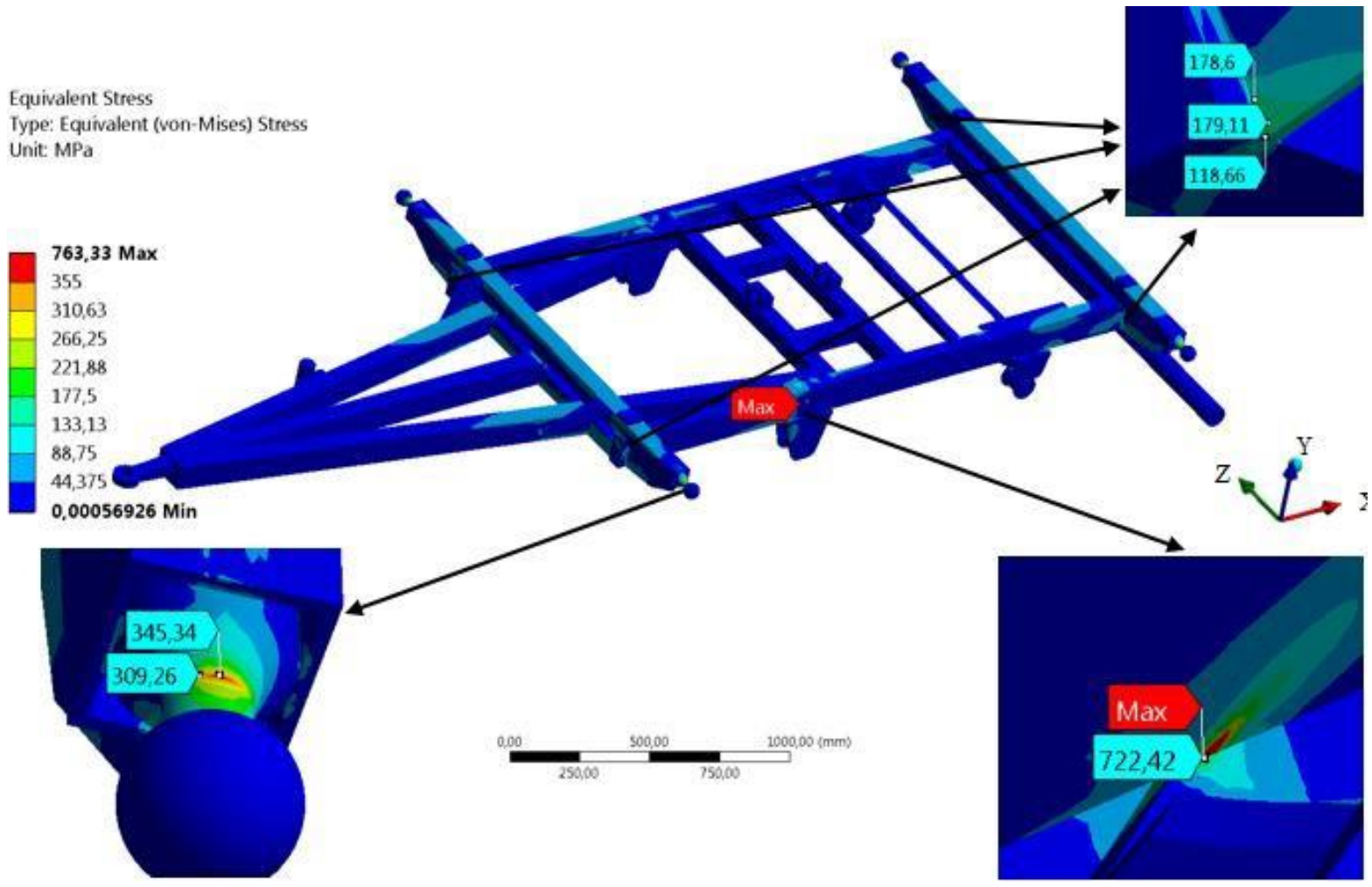

Fig. 9. Distribution of von Misses stresses in the frame structure for the first load case

Another analysed situation is the second load case. It relates to back tipping manoeuvre. Force values are defined according to the analytical results (Table 1) and locations of these forces are defined in Fig. 4. The results of the strength analysis can be seen in Fig. 10. 


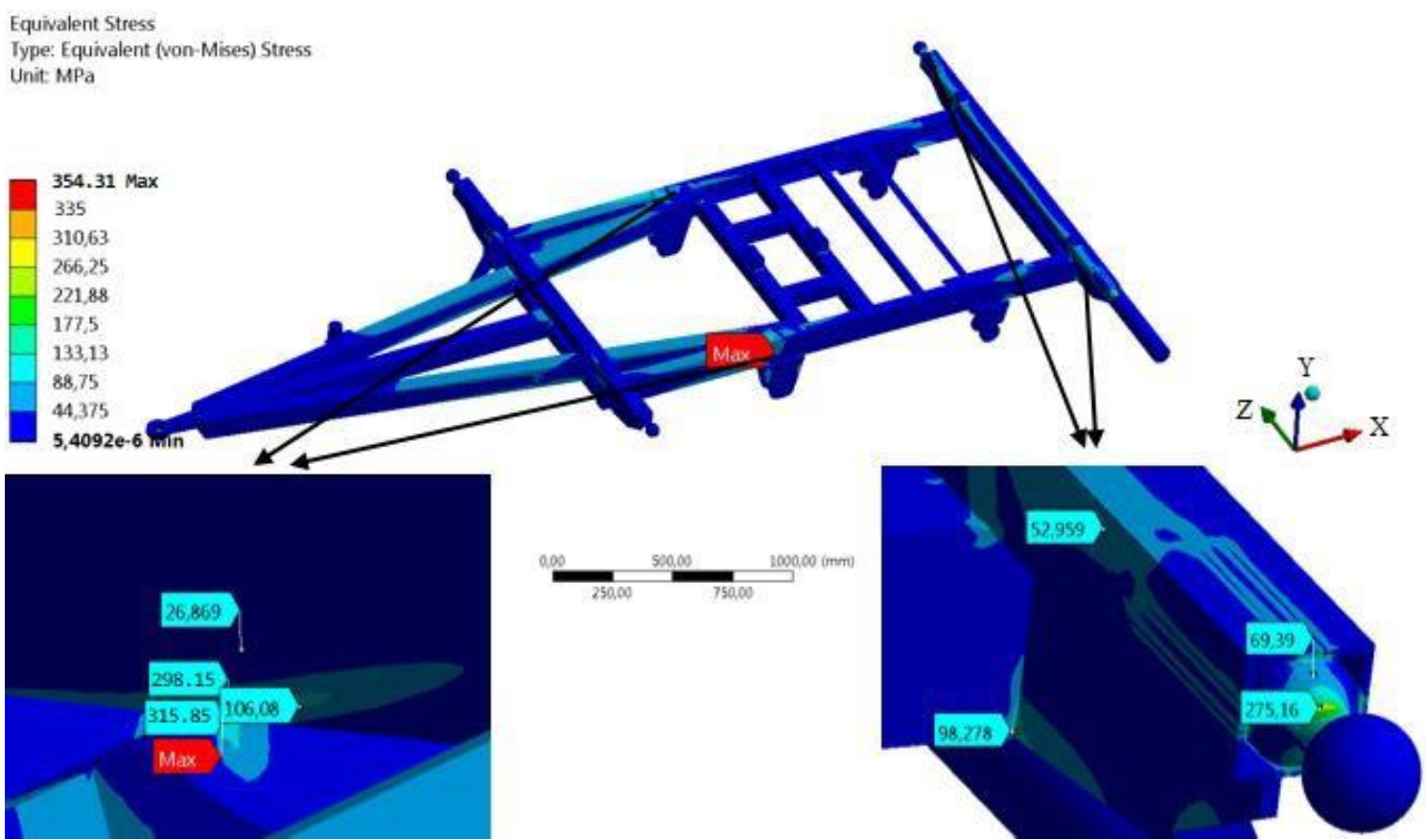

Fig. 10. Distribution of von Misses stresses in the frame structure for the second load case

The results show locations with maximal stress locations. As it can be seen on enlarged details, the maximal stress values are mainly in joints of the drawbar profiles and two longitudinal profiles of the frame (Fig. 10, left below) and in the structure of normalized ball joints (Fig. 10, right below). These results are safely under the yield strength and the structure of the trailer frame for the second load case can be evaluated as safe.

Finally, the third load case has been analysed. It is the side tipping process. The superstructure is tilted to the left and the load forces act to the frame structure in two side ball joints and in the beams carrying the hydraulic cylinder in the centre part. A stress distribution, as well as the chosen details showing the most loaded location of the frame are shown in Fig. 11.

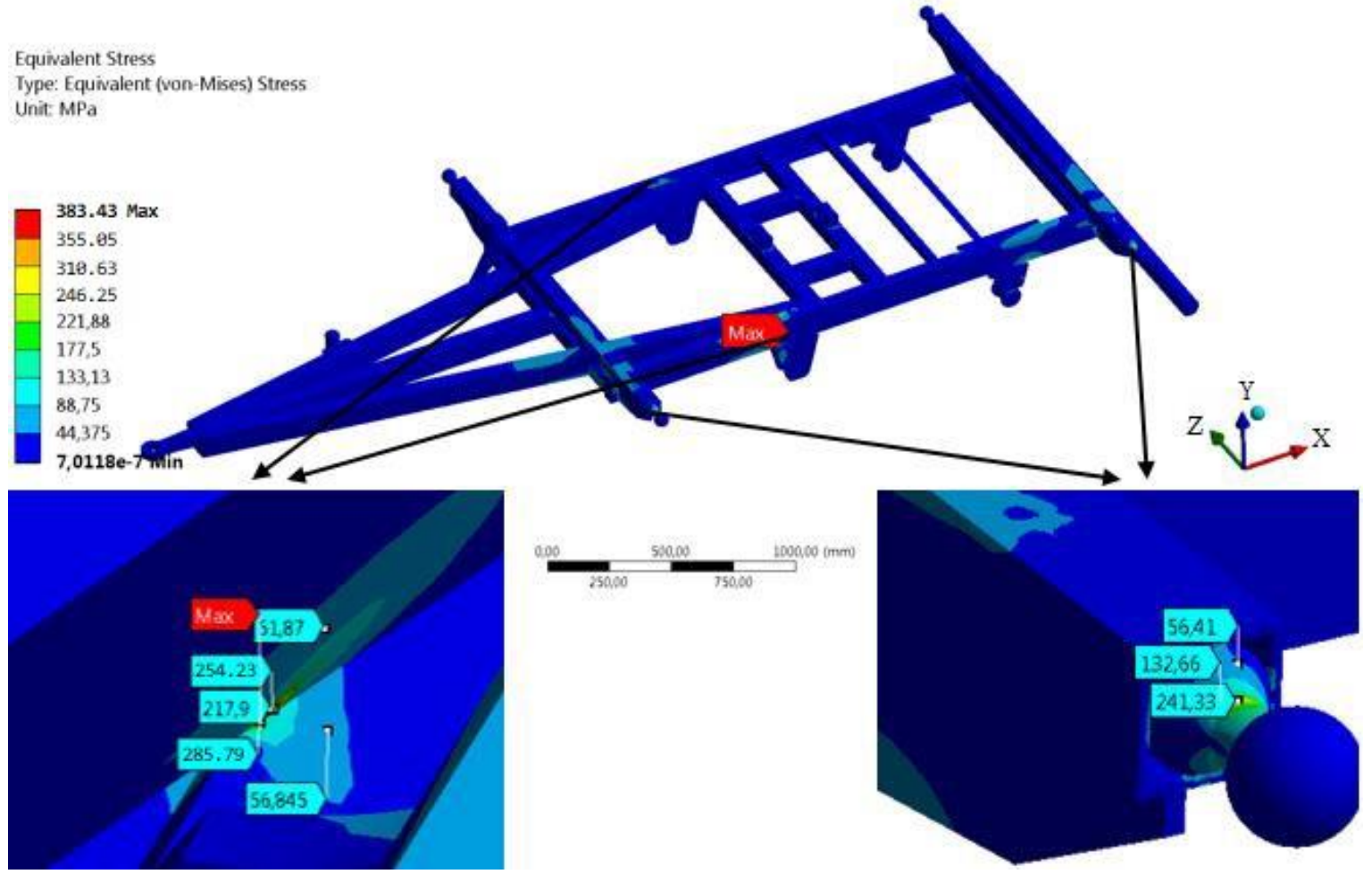

Fig. 11. Distribution of von Misses stresses in the frame structure for the third load case 
The stress distribution reveals the structural stress of the trailer frame under defined forces. The most loaded locations are again in the connection of the drawbar profiles with the longitudinal profiles, mainly on the left (where the superstructure is tilted). Even in the third load case the normalized ball joints belong to the most loaded elements of the trailer frame structure. All detected stresses are under the yield of strength of the used steel and, therefore, the structure is supposed as safe.

The performed strength analyses of the trailer frame have shown that the designed frame structure is able to carry considered loads in the static or quasi-static operational states. Dynamic effects are included by means of the dynamic coefficient $\delta_{D}$. Therefore, it can be concluded that the frame structure is safe.

Based on the reached results of the strength analyses of the frame, it can be concluded that the structure of the trailer can be supposed to be applied to the operation. Although, some values of the results are close to maximal permissible values of the yield of strength of the used material, however, they are normalized parts, such as ball joints. These parts are bought from the external supplier and they are also used for other producers for similar products and even for higher loads.

As the superstructure of the trailer there is also the newly designed part of the trailer, this should be analysed in terms of the strength as well. These analyses will also include definition of important load cases, in which the superstructure frame will be maximally loaded.

The future research will be mainly focused on analysing of the dynamic effects to the structure. Despite of the considered dynamic coefficient, the state of art simulation tools are able to simulate driving of the trailer on the various road surface qualities depending on the road irregularities level. The multibody simulations serve for it [17]. As the geometry of the frame, as well as the FE models are created, they can be suitable inputs to set-up the so-called flexible multibody model [18; 19]. Such a model will be good way to identify the stress distribution during driving for various manoeuvres, during tipping manoeuvers, or also for exceptional load cases, which can occur during the trailer long-term operation.

\section{Conclusions}

1. A single-axle tractor trailer has been designed. It is primary intended to be used as a tipper trailer.

2. The trailer structure consists of two main substructures, i.e. a chassis frame and a tipping superstructure frame.

3. The article presented the strength analyses of the chassis frame for the three particular static load cases representing the typical load cases of the trailer during operation.

4. The results of the strength analyses have shown that the trailer chassis frame is suitable to carry the loads for defined manoeuvres within prescribed limits.

\section{Acknowledgements}

This work was supported by the Cultural and Educational Grant Agency of the Ministry of Education of the Slovak Republic in the project No. KEGA 023ŽU-4/2020: Development of advanced virtual models for studying and investigation of transport means operation characteristics.

\section{References}

[1] Figlus T., Kuczyński Ł. Selection of a semi-trailer for the haulage of long oversize loads, taking into account an analysis of operational damage. Proceedings of International conference "XI International Science-Technical Conference Automotive Safety", April 18-20, 2018, ČastáPapiernička, Slovakia, pp. 1-5.

[2] Medvecká-Beňová S. Strength analysis of the frame of a trailer. Scientific Journal of Silesian University of Technology. Series Transport, Vol. 96, 2017, pp. 105-113.

[3] Skrúcaný T., Vrábel J., Kendra M., Kažimír P. Impact of cargo distribution on the vehicle flatback on braking distance in road freight transport. MATEC Web of Conferences, Vol. 134, 2017.

[4] Gardynski L., Caban J., Barta, D. Research of composite materials used in the construction of vehicle bodywork. Advanced in Science and Technology -Research Journal, Vol. 12, 2018, pp. 181-187. 
[5] Droppa P., Filípek S., Čornák Š. The possibilities of using diagnostics and simulation methods to design and modernization of military technics. Proceedings of $20^{\text {th }}$ International Scientific Conference on Transport Means "TRANSPORT MEANS 2016", October 5-7, 2016, Juodkrante, Lithuania, pp. 156-160.

[6] Slovak promulgation No. 134/2018 "Details about operation of vehicles in road traffic" (In Slovak).

[7] Regulation (EU) No 167/2013 of the European Parliament and of the Council "On the approval and market surveillance of agricultural and forestry vehicles".

[8] Regulation (EU) No 168/2013 of the European Parliament and of the Council "On the approval and market of two- and three-wheel vehicles and quadricycles".

[9] Regulation of the Slovak Republic government No. 140/2009 "Details about types commissioning of engine vehicles and their trailer, systems, components and individual technical units determined for these vehicles" (In Slovak).

[10] Leitner B. Autoregressive Models in Modelling and Simulation of Transport Means Working Conditions. Proceedings of $14^{\text {th }}$ International Scientific Conference on Transport Means “TRANSPORT MEANS 2010”, October 21-22, 2010, Kaunas, Lithuania, pp. 21-24.

[11] Kostrzewski M. Analysis of selected acceleration signals measurements obtained during supervised service conditions -study of hitherto approach. Journal of Vibroengineering, Vol. 20, 2018, pp. 1850-1866.

[12]Bajla, J., Bronček, J., Antala, J., Sekerešová, D. Mechanical Engineering Tables (In Slovak). Selection Standards. Slovak Office of Standards, Metrology and Testing, 2014.

[13] Fomin O., Gerlici J., Lovska A., Kravchenko K., Prokopenko P., Fomina A., Hauser V. Durability determination of the bearing structure of an open freight wagon body made of round pipes during its transportation on the railway ferry. Communications - Scientific Letters of the University of Zilina, vol. 21, 2019, pp. 28-34.

[14] Št’astniak P., Kurčík P., Pavlík A. Design of a new railway wagon for intermodal transport with the adaptable loading platform. MATEC Web of Conferences, vol. 235, 2018.

[15] Jakubovicova L., Sapietova A., Moravec J. Static analysis of transmission tower beam structure. MATEC Web of Conference, vol. 244, 2018.

[16] Handrik M., Kopas P., Baniari V., Vasko M., Saga M. Analysis of stress and strain of fatigue specimens localized in the cross-sectional area of the gauge section testing on bi-axial fatigue machine loaded in the high-cycle fatigue region. Procedia Engineering, Vol. 177, 2017, pp. 516519.

[17] Hauser V., Nozhenko O., Kravchenko K., Loulova M., Gerlici J., Lack T. Proposal of a steering mechanism for tram bogie with three axle boxes. Procedia Engineering, vol. 192, 2017, pp. 289294.

[18] Gerlici J., Sakhno V., Yefymenko A., Verbitskii V., Kravchenko A., Kravchenko K. The stability analysis of two-wheeled vehicle model. MATEC Web of Conferences, vol. 157, 2018.

[19] Harušinec J., Suchánek A., Loulová M., Strážovec P. Design of a device to simulate environmental influences on the course of brake tests. MATEC Web of Conferences, vol. 157, 2018. 